\title{
Size-Selective Adsorption in Nanoporous Polymers from Coumarin Photo-Cross-Linked Columnar Liquid Crystals
}

\author{
Alberto Concellón, ${ }^{\dagger}$ Albertus P. H. J. Schenning, ${ }^{\ddagger} \S_{(10}$ Pilar Romero, ${ }^{\dagger}$ Mercedes Marcos, ${ }^{\dagger}$ \\ and José Luis Serrano*,ll \\ ${ }^{\dagger}$ Instituto de Ciencia de Materiales de Aragón, Departamento de Química Orgánica, Universidad de Zaragoza-CSIC, 50009 Zaragoza, \\ Spain \\ ${ }^{\ddagger}$ Department of Functional Organic Materials and Devices, Chemical Engineering and Chemistry, and ${ }^{\S}$ Institute for Complex \\ Molecular Systems (ICMS), Eindhoven University of Technology, P.O. Box 513, 5600 MB Eindhoven, The Netherlands \\ "Instituto de Nanociencia de Aragón, Departamento de Química Orgánica, Universidad de Zaragoza, 50009 Zaragoza, Spain
}

Supporting Information

ABSTRACT: We have prepared nanoporous polymers from columnar hexagonal hydrogen-bonded complexes, whose order is fixed by coumarin photoinduced $[2+2]$ cycloaddition (photodimerization). Two different hydrogen-bonded complexes were used and consisted of a melamine (M) or tris(triazolyl)triazine ( $\mathbf{T}$ ) derivative acting as central templates and three peripheral carboxylic acids containing coumarin units. These coumarin units were employed for the cross-linking process by photodimerization in order to fix the LC arrangement. Template removal leads to the formation of self-standing nanoporous polymers keeping the

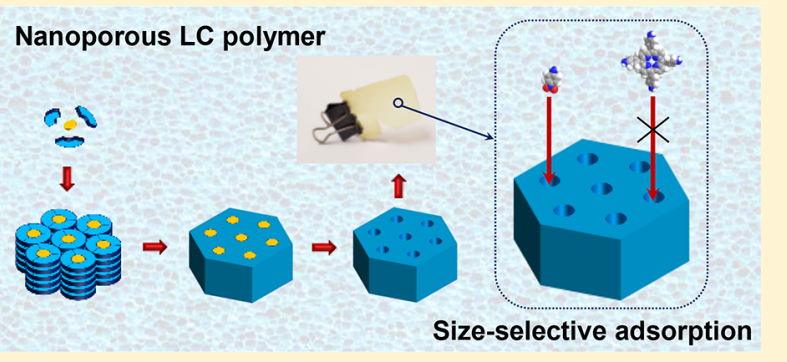
columnar hexagonal order. Two nanoporous polymers with different pore diameters were obtained depending on size of the utilized template. These polymers with carboxylic acids at the pore surface demonstrate the ability to selectively adsorb certain molecules depending on their size. Moreover, after base treatment of the nanoporous polymers, they are able to adsorb cationic dyes over anionic and larger cations, demonstrating size- and charge-selective adsorption.

\section{INTRODUCTION}

Nanoporous materials, with a pore size of $100 \mathrm{~nm}$ or smaller, have attracted considerable attention due to their commercial use in areas such as filtration, separation, catalysis, and drug delivery. The nanosized pores allow the discrimination between molecules or ions based on size and shape. Mimicking biological cell membranes, material scientists have prepared different nanoporous systems mostly based on inorganic materials such as silica, zeolites, and metals. ${ }^{1-3}$ However, the use of organic polymeric materials that are much easier to modify and tune for specific applications has been less often explored. ${ }^{4,5}$

Among polymeric materials, those derived from the microphase separation of block copolymers have been broadly exploited for the preparation of polymers with a pore size from 5 to $50 \mathrm{~nm} .^{6}$ In an attempt to create smaller pore dimensions, many research groups started to investigate the use of polymerizable supramolecular liquid crystals (LCs) to prepare porous materials with pore sizes of around $1 \mathrm{~nm}^{7-9}$ The general approach to prepare thermotropic LC nanoporous materials consists of using hydrogen bonding in the core of the mesogenic unit. The nanopores are obtained after breaking of the hydrogen bonds or removal of an hydrogen bonded template. In addition, it is also possible to control the morphology of the nanopores by careful choice of the mesophase. LCs showing columnar mesophases may lead to the formation of $1 \mathrm{D}$ pores in the direction of the columnar axes. ${ }^{10-13} 2 \mathrm{D}$ morphologies can be obtained by using smectic LCs with the pores in the directions within the layer plane. ${ }^{14-17}$

Pioneering work on 1D nanoporous materials by Kim and co-workers ${ }^{18}$ has been followed by an increasing interest in these systems where a very common approach is based on the use of $C_{3}$ symmetric templates and pro-discotic mesogenic units connected by hydrogen bonding. ${ }^{19-26}$ Cross-linking of such noncovalent LCs followed by template removal can yield materials with nanopores replicating the size of the molecular templates. The resultant pores are expected to incorporate guest molecules that resemble the original template.

In our research group, we have shown several examples of hydrogen-bonded complexes using melamine or tris(triazolyl)triazine as template molecules. ${ }^{27,28}$ Both templates can be functionalized by hydrogen bonding with benzoic acids leading to $1: 3$ complexes with columnar hexagonal mesomorphism. Herein, we report on the preparation nanoporous polymers by using two hydrogen-bonded complexes that displayed columnar hexagonal mesomorphism. The materials used in this work

Received: January 12, 2018

Revised: March 6, 2018 
(a)
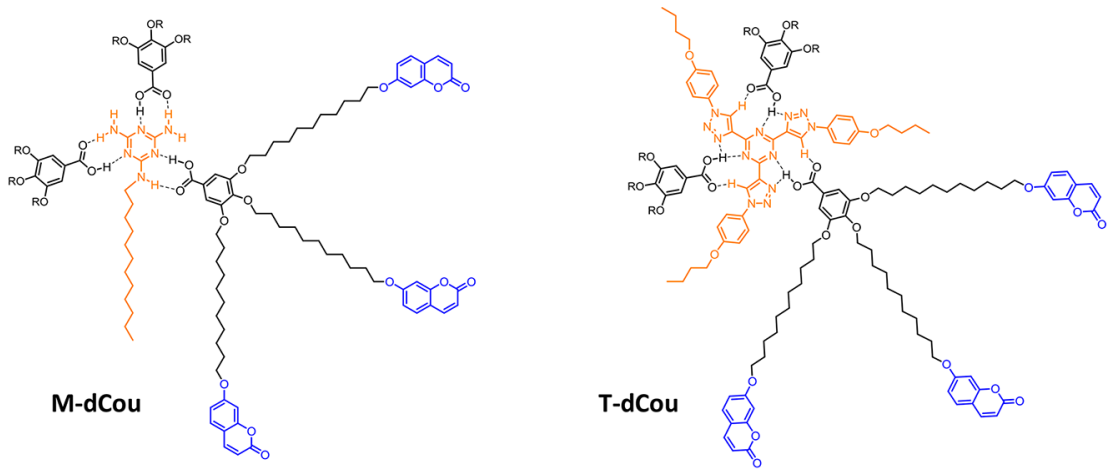

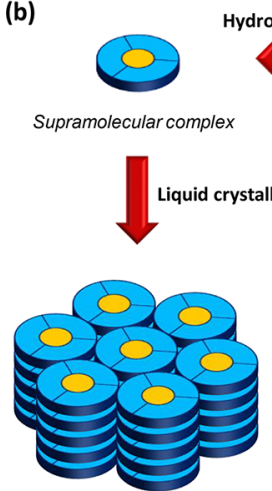

Columnar hexagonal mesophase
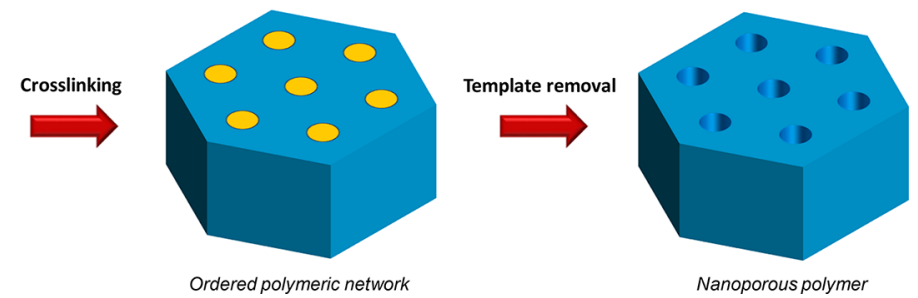

Figure 1. (a) Chemical structure of the supramolecular complexes and (b) schematic representation of the process for the preparation of the nanoporous polymers.

consist of a melamine $(\mathbf{M})$ or tris(triazolyl)triazine $(\mathbf{T})$ core hydrogen bonded to three dendrons derived from a 3,4,5trialkoxycarboxylic acid bearing coumarin moieties (dCou) (Figure 1a). In this work coumarin was chosen as reactive group for the cross-linking reaction. Upon UV irradiation, coumarins undergo $[2+2]$ cycloaddition to yield cyclobutane dimers. It does not require an initiator or catalyst, and side reactions are avoided. Photodimerization has been exploited as a cross-linking reaction in material science for the preparation of proton-conductive LC networks, ${ }^{29}$ light-responsive nanoparticles, $^{30,31}$ or micropatterned surfaces. ${ }^{32}$

The nanoporous materials were obtained by using the columnar hexagonal complexes, cross-linking via coumarin photodimerization, followed by quantitative template removal (Figure 1b). To our knowledge, this is the first report of mesophase fixation by coumarin photodimerization for preparing nanoporous polymers instead of the more common photopolymerization of (meth)acrylates or 1,3-dienyl groups. Furthermore, the use of both templates allowed us to control the pore size and, accordingly, to tune the adsorption selectivity of the nanoporous polymers.

\section{EXPERIMENTAL SECTION}

Preparation of the Hydrogen-Bonded Complexes. 3,4,5Tris((11-((2-oxo-2H-chromen-7-yl)oxy)undecyl)oxy)benzoic acid (dCou), 2,4-diamino-6-dodecylamino-1,3,5-triazine (M), and 2,4,6tris $\left[1^{\prime}\right.$-(4"'-butoxyphenyl)-1',2',3'-triazol-4' -yl]-1,3,5-triazine ( $\left.\mathrm{T}\right)$ were synthesized by previously reported procedures. ${ }^{27,28,33}$ For the preparation of the hydrogen-bonded complexes, the required amounts of the carboxylic acid $\mathbf{d C o u}$ and the corresponding core $\mathbf{M}$ or $\mathbf{T}$ were weighted (3:1 molar ratio) and dissolved in dichloromethane. The solvent was slowly evaporated at RT, and the mixtures were dried under vacuum at $30{ }^{\circ} \mathrm{C}$ for at least 2 days. Finally, the mixtures were heated to their isotropic states and then cooled down slowly to room temperature before used for further experiments.

M-dCou. IR (KBr) $\nu\left(\mathrm{cm}^{-1}\right): 3347(\mathrm{~N}-\mathrm{H}), 3086(=\mathrm{C}-\mathrm{H}), 2921$ $(\mathrm{C}-\mathrm{H}), 1728,1688(\mathrm{C}=\mathrm{O}), 1610,1589,1553,1510(\mathrm{Ar}), 1223$, $1116(\mathrm{C}-\mathrm{O}) .{ }^{1} \mathrm{H}$ NMR $\left(500 \mathrm{MHz}, \mathrm{CD}_{2} \mathrm{Cl}_{2}\right) \delta(\mathrm{ppm}): 7.69-7.59(\mathrm{~m}$, $\left.9 \mathrm{H} ; H_{\mathrm{C}}\right), 7.40-7.33\left(\mathrm{~m}, 9 \mathrm{H} ; H_{\mathrm{E}}\right), 7.30\left(\mathrm{~s}, 6 \mathrm{H} ; H_{\mathrm{P}}\right), 6.86-6.75(\mathrm{~m}$, $18 \mathrm{H} ; H_{\mathrm{F}}$ and $\left.H_{\mathrm{H}}\right), 6.30\left(\mathrm{t}, 1 \mathrm{H}, J=5.6 \mathrm{~Hz} ; H_{\varepsilon}\right), 6.22-6.14(\mathrm{~m}, 9 \mathrm{H}$; $\left.H_{\mathrm{B}}\right), 6.11-5.96\left(\mathrm{~m}, 4 \mathrm{H} ; H_{\alpha}\right), 4.66\left(\mathrm{~s}_{\text {broad }}, 1 \mathrm{H} ; H_{\mathrm{T}}\right), 4.11-3.91(\mathrm{~m}$, $36 \mathrm{H} ; H_{\mathrm{J}}$ and $\left.H_{\mathrm{N}}\right), 3.45-3.25\left(\mathrm{~m}, 2 \mathrm{H} ; H_{\zeta}\right), 1.88-1.68\left(\mathrm{~m}, 36 \mathrm{H} ; H_{\mathrm{K}}\right.$ and $\left.H_{\mathrm{M}}\right), 1.62-1.18\left(\mathrm{~m}, 146 \mathrm{H} ; H_{\eta}, H_{\theta}\right.$ and $\left.H_{\mathrm{L}}\right), 0.87(\mathrm{t}, 3 \mathrm{H}, J=7.0$ $\left.\mathrm{Hz} ; H_{\kappa}\right) .{ }^{13} \mathrm{C}$ NMR $\left(125 \mathrm{MHz}, \mathrm{CD}_{2} \mathrm{Cl}_{2}\right) \delta(\mathrm{ppm}): 170.57,164.73$, $162.90,161.36,156.41,153.29,143.82,142.95,129.20,125.32,113.24$, $113.17,112.85,108.60,101.66,73.85,69.59,69.20,41.26,32.35$, $30.77,30.11,30.03,30.00,29.96,29.80,29.78,29.77,29.46,29.43$, 27.27, 26.51, 26.40, 26.36, 23.11, 14.30. Anal. Calcd for $\mathrm{C}_{216} \mathrm{H}_{282} \mathrm{~N}_{6} \mathrm{O}_{42}:$ C, $71.38 \%$; H, 7.82\%; N, $2.31 \%$. Found: C, $71.12 \%$; $\mathrm{H}, 8.00 \%$; N, $2.22 \%$.

T-dCou. IR $(\mathrm{KBr}) \nu\left(\mathrm{cm}^{-1}\right): 3079(=\mathrm{C}-\mathrm{H}), 2920(\mathrm{C}-\mathrm{H}), 1729$, $1695(\mathrm{C}=\mathrm{O}), 1611,1582,1555,1505(\mathrm{Ar}), 1226,1117(\mathrm{C}-\mathrm{O}) .{ }^{1} \mathrm{H}$ NMR (500 MHz, $\left.\mathrm{CD}_{2} \mathrm{Cl}_{2}\right) \delta(\mathrm{ppm}): 9.04\left(\mathrm{~s}, 3 \mathrm{H} ; \mathrm{H}_{3}\right), 7.84-7.75(\mathrm{~m}$, $\left.6 \mathrm{H} ; \mathrm{H}_{5}\right), 7.69-7.59\left(\mathrm{~m}, 9 \mathrm{H} ; H_{\mathrm{C}}\right), 7.41-7.33\left(\mathrm{~m}, 9 \mathrm{H} ; H_{\mathrm{E}}\right), 7.30(\mathrm{~s}$, $\left.6 \mathrm{H} ; H_{\mathrm{P}}\right), 7.13-7.07\left(\mathrm{~m}, 6 \mathrm{H} ; \mathrm{H}_{5}\right), 6.87-6.75\left(\mathrm{~m}, 18 \mathrm{H} ; H_{\mathrm{F}}\right.$ and $\left.H_{\mathrm{H}}\right)$, 6.22-6.15 (m, 9H; $\left.H_{\mathrm{B}}\right), 4.11-3.96\left(\mathrm{~m}, 42 \mathrm{H} ; H_{8}, H_{\mathrm{J}}\right.$, and $\left.H_{\mathrm{N}}\right), 1.89-$ $1.68\left(\mathrm{~m}, 42 \mathrm{H} ; H_{9}+H_{\mathrm{K}}\right.$ and $\left.H_{\mathrm{M}}\right), 1.60-1.22\left(\mathrm{~m}, 152 \mathrm{H} ; H_{10}\right.$ and $\left.H_{\mathrm{L}}\right)$, $1.01\left(\mathrm{t}, 6 \mathrm{H}, J=7.4 \mathrm{~Hz} ; \mathrm{H}_{11}\right) .{ }^{13} \mathrm{C} \mathrm{NMR}\left(125 \mathrm{MHz}, \mathrm{CD}_{2} \mathrm{Cl}_{2}\right) \delta(\mathrm{ppm})$ : $169.79,167.29,162.91,161.39,160.46,156.42,153.35,146.26,143.84$, $143.29,130.19,129.21,126.12,124.19,122.66,115.87,113.24,113.18$, $112.85,108.71,101.66,73.88,69.62,69.21,68.75,31.65,30.77,29.96$, 29.77, 29.43, 26.49, 26.36, 19.64, 14.02. Anal. Calcd for $\mathrm{C}_{240} \mathrm{H}_{294} \mathrm{~N}_{12} \mathrm{O}_{45}:$ C, $70.88 \% ; \mathrm{H}, 7.29 \% ; \mathrm{N}, 4.13 \%$. Found: C, $70.57 \% ; \mathrm{H}, 7.15 \%$; N, 3.98\%.

Preparation of the Self-Standing LC Polymer Networks. Poly(vinyl alcohol) (PVA) sacrificial layers were prepared onto glass substrates in order to facilitate network extraction after coumarin 


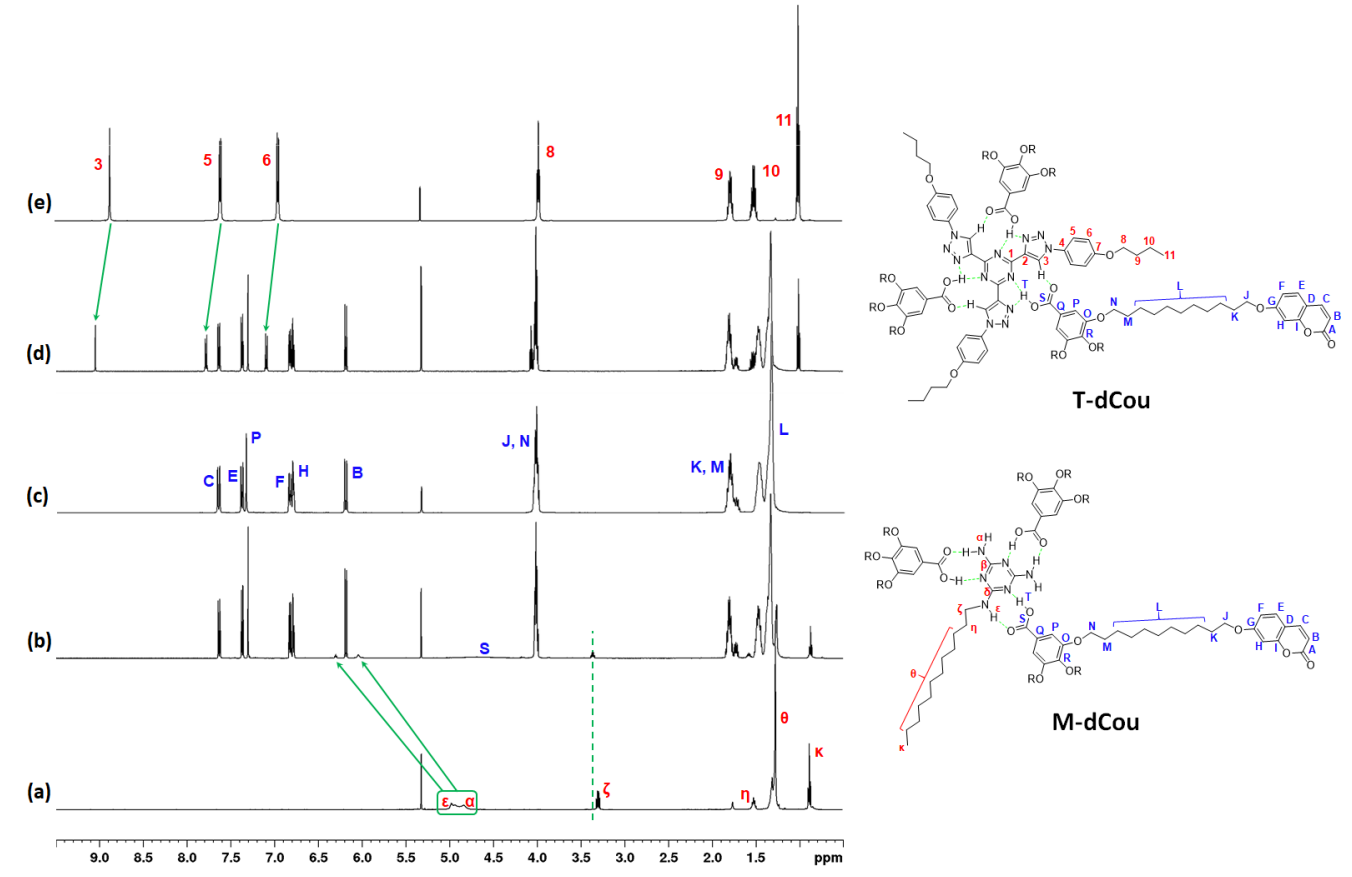

Figure 2. ${ }^{1} \mathrm{H}$ NMR spectra in $\mathrm{CD}_{2} \mathrm{Cl}_{2}$ solution at $25{ }^{\circ} \mathrm{C}$ of (a) $\mathbf{M}$, (b) 1:3 complex M-dCou, (c) dCou, (d) 1:3 complex T-dCou, and (e) T.

photodimerization. LC films were prepared by sandwiching a small amount of the supramolecular complex between two PVA-coated glass plates using silicon spacers of $10 \mu \mathrm{m}$. The system was heated to the isotropic state and slowly cooled down to RT $\left(0.1{ }^{\circ} \mathrm{C} \mathrm{min}{ }^{-1}\right)$. Then, the system was irradiated with a $365 \mathrm{~nm}$ LED light (ThorsLab) for 30 min (15 min each side). Finally, the system was immersed in water to dissolve the PVA layer in order to obtain the self-standing polymer films floating at the water surface. Then the films were dried under vacuum at RT for $5 \mathrm{~h}$.

Preparation of the Nanoporous Polymers by Template Elimination. For the elimination of $\mathbf{M}$ or $\mathbf{T}$ templates, polymer films were immersed in $5 \mathrm{~mL}$ of $3 \mathrm{M} \mathrm{HCl}$ in ethanol under orbital oscillation for $24 \mathrm{~h}$. Then the films were washed with water, ethanol and dried under vacuum at RT for $5 \mathrm{~h}$ to produce the nanoporous polymers.

Selective Adsorption of Neutral Molecules. $p$-Nitroaniline, 1aminopyrene, and meso-tetra( $p$-aminophenyl)porphine were dried prior to use and dissolved at a known concentration in methanol to get relatives absorbances of approximately 1 . The nanoporous polymers were cut into small pieces of approximately $1.0 \mathrm{mg}$, and were immersed in the $p$-nitroaniline, 1-aminopyrene, or meso-tetra( $p$ aminophenyl)porphine solutions. The films were allowed to adsorb the molecules at RT overnight. The adsorption behavior was monitored by UV-vis spectroscopy, and the dye concentration was calculated using the peak maximum. The sizes of $p$-nitroaniline, 1aminopyrene, and meso-tetra( $p$-aminophenyl $)$ porphine were calculated by the MM2 force field method using the Chem3D software package.

Selective Adsorption of Ionic Dyes. The dyes (methylene blue, methyl orange, and rhodamine B) were dried prior to use and dissolved at a known concentration in distilled water to get relatives absorbances of approximately 1 . The nanoporous polymers were cut into small pieces of approximately $1.0 \mathrm{mg}$ and were immersed in $0.1 \mathrm{M}$ $\mathrm{KOH}$ solution to deprotonate the carboxylic acid moieties. They were quickly washed with a few milliliters of distilled water to remove the residual base, and subsequently, they were added to the dye solution. The films were allowed to adsorb the molecules at RT overnight. The adsorption behavior was monitored by UV-vis spectroscopy, and the dye concentration was calculated using the peak maximum. The sizes of methylene blue, methyl orange, and rhodamine B were calculated by the MM2 force field method using the Chem3D software package.
Characterization Techniques. FTIR spectra were obtained on a FTS 6000 spectrophotometer from Bio-Rad equipped with Specac Golden gate diamond ATR; 50 scans at a resolution of $4 \mathrm{~cm}^{-1}$ were carried out. Solution NMR experiments were carried out on Bruker Avance spectrometers operating at $500 \mathrm{MHz}$ for ${ }^{1} \mathrm{H}$ and $125 \mathrm{MHz}$ for ${ }^{13} \mathrm{C}$, using standard pulse sequences. Chemical shifts are given in ppm relative to TMS, and this was used as internal reference. Solid-state NMR experiments were performed in a Bruker Avance III WB400 spectrometer using a double resonance $\left({ }^{1} \mathrm{H}-\mathrm{X}\right)$ probe with a rotor of 4 or $2.5 \mathrm{~mm}$ diameter, and the spinning frequency was set to 12 or 20 $\mathrm{kHz}$, respectively. For the former, the ${ }^{1} \mathrm{H}$ and ${ }^{13} \mathrm{C} \pi / 2$ pulse lengths were 3 and $4.3 \mu \mathrm{s}$, respectively, the $\mathrm{CP}$ contact time was $3 \mathrm{~ms}$, and the recycle delay was $7 \mathrm{~s}$. For the latter, the ${ }^{1} \mathrm{H}$ and ${ }^{13} \mathrm{C}$ pulse lengths were 8 and $5.7 \mu \mathrm{s}$, respectively, the CP contact time was $1.5 \mathrm{~ms}$, and the recycle delay was $5 \mathrm{~s}$. The pulse sequence employed consisted of ramped cross-polarization with spinal-64 decoupling. Data were acquired at $298 \mathrm{~K}$, and chemical shifts are referenced to TMS using adamantane $\left({ }^{13} \mathrm{C}: \delta=29.45 \mathrm{ppm}\right)$ as secondary standard. Mesogenic behavior was investigated by polarized-light optical microscopy (POM) using an Olympus $\mathrm{BH}-2$ polarizing microscope fitted with a Linkam THMS600 hot stage. Thermogravimetric analysis (TGA) was performed using a Q5000IR from TA Instruments at heating rate of 10 ${ }^{\circ} \mathrm{C} \min ^{-1}$ under a nitrogen atmosphere. Thermal transitions were determined by differential scanning calorimetry (DSC) using a DSC Q2000 from TA Instruments with powdered samples (2-5 mg) sealed in aluminum pans. Glass transition temperatures $\left(T_{\mathrm{g}}\right)$ were determined at the half-height of the baseline jump, and first-order transition temperatures were read at the maximum of the corresponding peak. X-ray diffraction (XRD) was performed with a Ganesha lab instrument equipped with a GeniX-Cu ultralow divergence source producing X-ray photons with a wavelength of $1.54 \AA$ and a flux of $1 \times 10^{8}$ photons $\mathrm{s}^{-1}$. Scattering patterns were collected using a Pilatus $300 \mathrm{~K}$ silicon pixel detector. The beam center and the $q$ range were calibrated using the diffraction peaks of silver behenate. Powdered samples were placed in Lindemann glass capillaries (1 mm diameter). UV-vis absorption spectra were recorded on a Shimadzu UV-3102 spectrophotometer. The XPS measurements were carried out with a Thermo Scientific K-Alpha, equipped with a monochromatic small-spot X-ray source and a $180^{\circ}$ double focusing hemispherical analyzer with a 128-channel detector. Spectra were obtained using an aluminum anode $(\mathrm{Al} \mathrm{K} \alpha=1486.6 \mathrm{eV})$ operating at $72 \mathrm{~W}$ and a sport size of $400 \mu \mathrm{m}$. Survey scans were measured at a 
constant pass energy of $200 \mathrm{eV}$ and region scans at $50 \mathrm{eV}$. The background pressure was $2 \times 10^{-9}$ mbar and during measurement $3 \times$ $10^{-7}$ mbar argon because of the charge compensation for the dual beam source.

\section{RESULTS AND DISCUSSION}

Preparation and Characterization of Supramolecular Hydrogen-Bonded Complexes. The carboxylic acid bearing coumarin moieties (dCou), ${ }^{33}$ the melamine core $(\mathbf{M}),{ }^{27}$ and the tris(triazolyl)triazine core $(\mathrm{T})^{28}$ were synthesized following previously reported procedures. The hydrogen-bonded complexes were prepared by dissolving $\mathbf{d C o u}$ and the corresponding core $(\mathbf{M}$ or $\mathbf{T})$ in a 1:3 ratio in dichloromethane followed by slow evaporation of the solvent under continuous stirring at room temperature. The resulting mixtures were heated to the isotropic state and cooled down slowly to room temperature. The formation of intermolecular hydrogen bonds in the complexes was study by infrared spectroscopy (FTIR) and nuclear magnetic resonance (NMR).

FTIR spectra of the complexes displayed several changes with respect to dCou and the cores due to the formation of specific interactions between the carboxylic acid and $\mathbf{M}$ or $\mathbf{T}$ (Figure $\mathrm{S} 1$ ). In the dCou spectrum, a $\mathrm{C}=\mathrm{O}$ stretching band appeared at $1670 \mathrm{~cm}^{-1}$, which corresponds to the dimeric form of the carboxylic acid. In the FTIR spectra of M-dCou and TdCou, this $\mathrm{C}=\mathrm{O}$ stretching band was shifted respectively to 1687 and $1695 \mathrm{~cm}^{-1}$ due to hydrogen-bonding interactions between complementary $\mathbf{d C o u}$ and $\mathbf{M}$ or $\mathbf{T}$.

The ${ }^{1} \mathrm{H}$ NMR spectra of the complexes also proved the hydrogen bonds formation in the complexes, assuming that there is a rapid equilibrium between the complex and its components. In general, proton signals involved in hydrogen bonds, as well as those that are close to the complexing groups, experienced correlated changes in their chemical shifts (Figure 2). The formation of hydrogen bonds in the M-dCou complex was assessed by the downfield shift of the $\mathrm{N}-\mathrm{H}\left(H_{\alpha}\right.$ and $\left.H_{\varepsilon}\right)$ proton signals of the $\mathbf{M}$ core as these protons are involved in the hydrogen bonds with dCou. In the case of T-dCou, the triazole protons $\left(\mathrm{H}_{3}\right)$ experienced a downfield displacement, indicating that these protons interact through hydrogen bonding with the carbonyl group of dCou. Besides, it is particularly noteworthy that in both complexes the protons close to the hydrogen bonds experience slight displacements. These shift variations of the signals of the main protons involved in complex formation are listed in Table S1 of the Supporting Information.

On the other hand, variations in the chemical shifts of the ${ }^{13} \mathrm{C}$ signals of the carbon atoms involved in the formation of hydrogen bonds were also observed. In particular, the ${ }^{13} \mathrm{C}$ signals of the carboxylic acid group of dCou are shifted by $-0.62 \mathrm{ppm}$ (for M-dCou) or $-1.40 \mathrm{ppm}$ (for T-dCou) after complexation. The shift variations of the signals of the main carbons involved in complex formation are listed in Table S2.

The formation of the 1:3 hydrogen-bonded complexes was also confirmed by solid state ${ }^{13} \mathrm{C}$ cross-polarization magic-angle spinning $\left({ }^{13} \mathrm{C}\right.$ CPMAS) NMR spectroscopy; see Figure 3 as a representative example. It is noteworthy that the peak corresponding to the carbonyl group of the noncomplexed acid $\left(C_{S}\right)(172.5 \mathrm{ppm})$ is broadened and shifted in the spectrum of the complexes. Moreover, the signals for some carbon atoms, of both the dCou and the cores, are significantly shifted upon complexation, but it is difficult to assign these shifts due to signal overlap.

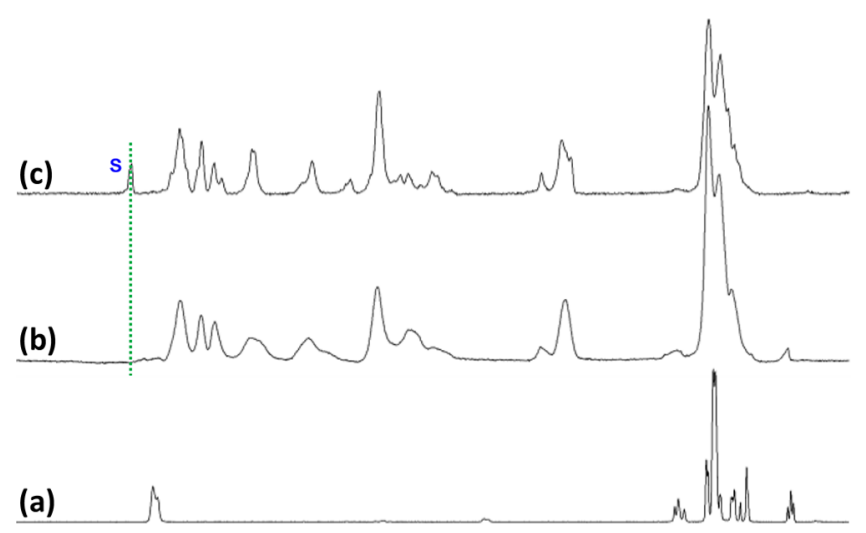

$\begin{array}{lllllllllllllllllll}190 & 180 & 170 & 160 & 150 & 140 & 130 & 120 & 110 & 100 & 90 & 80 & 70 & 60 & 50 & 40 & 30 & 20 & \text { ppm }\end{array}$

Figure 3. ${ }^{13} \mathrm{C}$ CPMAS NMR spectra of (a) $\mathbf{M}$, (b) complex M-dCou, and (c) dCou. All the spectra were recorded at room temperature.

Thermal Properties and Mesogenic Behavior. The thermal stability of the two hydrogen-bonded complexes was studied by thermogravimetric analysis (TGA). All the samples showed good thermal stability, and in all cases the $2 \%$ weight loss temperature $\left(T_{2 \%}\right)$ was detected more than $150{ }^{\circ} \mathrm{C}$ above the isotropization point (Table 1 ). The thermal transitions and mesomorphic properties were studied by polarizing optical microscopy (POM) and differential scanning calorimetry (DSC).

All the complexes were obtained as homogeneous materials with mesomorphic behavior, as observed by POM (Figure S2). For the two compounds the DSC curves were reproducible after the first heating and show only one peak corresponding to the clearing point and a glass transition, which freezes the mesomorphic order at room temperature (Figure 4a). Besides, the complex T-dCou showed some tendency to crystallize because the mesophase undergoes a cold crystallization during the heating process.

The assignment of the type of mesophase and the determination of the lattice parameters were achieved by Xray diffraction (XRD). The XRD patterns of $\mathbf{M}$-dCou and TdCou contain three reflections in the low-angle region in a ratio $1: 1 / \sqrt{ } 3: 1 / \sqrt{ } 4$ (Figure $4 \mathrm{~b}$ ). These three reflections can be assigned to the reflections (100), (110), and (200) of a columnar hexagonal arrangement; the lattice parameters $(a)$ are gathered in Table 1. The broad diffuse halo is also observed in the high-angle region, which is characteristic of the liquidlike order of the hydrocarbon chains at around $4.5 \AA$. The relationship between the density $(\rho)$ of the complexes in the mesophase and the measured lattice parameters is given by the equation

$$
\rho=M Z / N_{\mathrm{A}} V
$$

where $M$ is the molar mass, $Z$ is the number of molecules in the unit cell, $N_{\mathrm{A}}$ is Avogadro's number, and $V$ is the unit cell volume $\left(V=a^{2} \cdot \sqrt{3 / 2 \cdot c \cdot 10^{-24}}\right)$. On considering the XRD parameters and assuming $\rho=1 \mathrm{~g} \mathrm{~cm}^{-3}$, which is reasonable for liquid crystals, and $Z=1$ (each column slice contains one molecule of the supramolecular complex), we estimated mean stacking distances $(c)$ of around $5.25 \AA$, which are reasonable values for columnar mesophases with an irregular stacking of the disks. Therefore, these calculations are in good agreement with the formation of discotic 1:3 complexes with one complex per stacking unit. 
Table 1. Thermal Properties and Structural Parameters

\begin{tabular}{|c|c|c|c|c|c|}
\hline & $T_{2 \%}{ }^{a}\left[{ }^{\circ} \mathrm{C}\right]$ & phase transitions $^{b}$ & $d[\AA]$ & $h k l$ & structural parameters $^{c}[\AA]$ \\
\hline M-dCou & 248 & g $16 \mathrm{Col}_{\mathrm{h}} 87 \mathrm{I}$ & $\begin{array}{l}31.2 \\
18.1 \\
15.7 \\
4.5 \text { (br) }\end{array}$ & $\begin{array}{lll}1 & 0 & 0 \\
1 & 1 & 0 \\
2 & 0 & 0 \\
\text { alkyl chains }\end{array}$ & $\begin{array}{l}a=36.1 \\
c=5.3^{d}\end{array}$ \\
\hline T-dCou & 292 & $\mathrm{~g} 9 \mathrm{Col}_{\mathrm{h}} 58 \mathrm{Cr} 86 \mathrm{I}$ & $\begin{array}{l}33.4 \\
19.1 \\
4.6 \text { (br) }\end{array}$ & 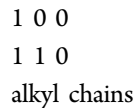 & $\begin{array}{l}a=38.4 \\
c=5.2^{d}\end{array}$ \\
\hline
\end{tabular}

${ }^{a}$ Temperature at which $2 \%$ mass lost is detected in the thermogravimetric curve. ${ }^{b} \mathrm{DSC}$ data of the second heating process at a rate of $10{ }^{\circ} \mathrm{C}$ min ${ }^{-1}$ g: glass; $\mathrm{Col}_{\mathrm{h}}$ : columnar hexagonal mesophase; I: isotropic liquid. ${ }^{c} a=(2 / \sqrt{3}) \cdot\left(d_{10}+\sqrt{ } 3 \cdot d_{11}+\sqrt{ } 4 \cdot d_{20}+\sqrt{ } 7 \cdot d_{21}+\ldots\right) / n_{\text {reflections }}{ }^{d}$ Calculated $c$ value.
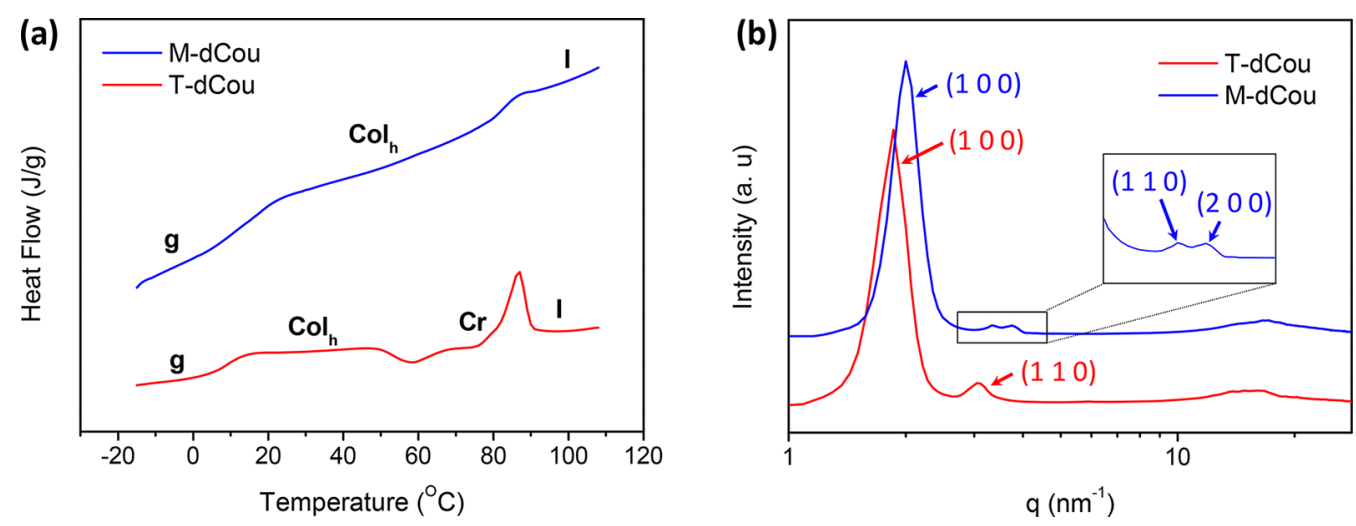

Figure 4. (a) DSC traces corresponding to the second heating scan $\left(10^{\circ} \mathrm{C} \min ^{-1}\right.$, exo down) and (b) $1 \mathrm{D}$ XRD profiles of 1:3 M-dCou and T-dCou complexes.

(a)
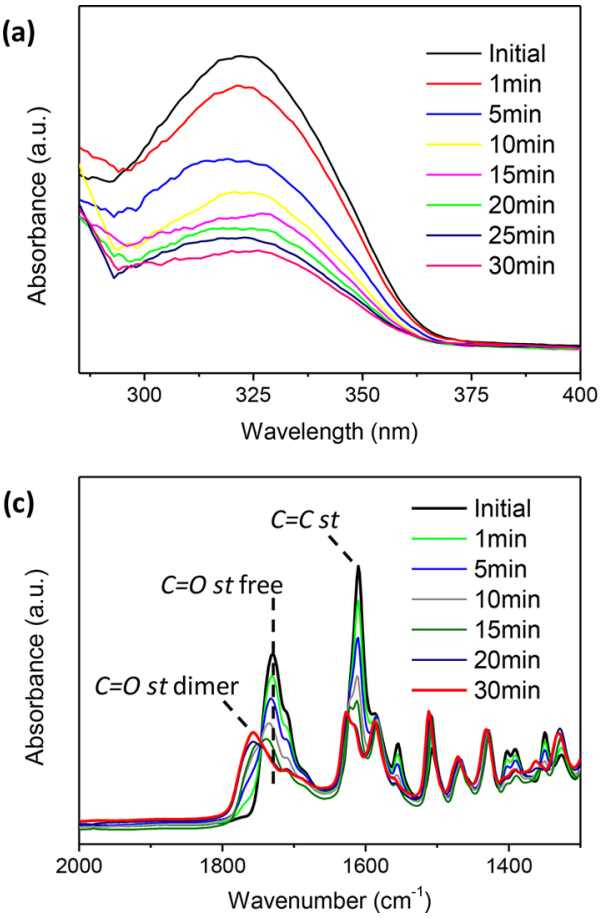

(b)
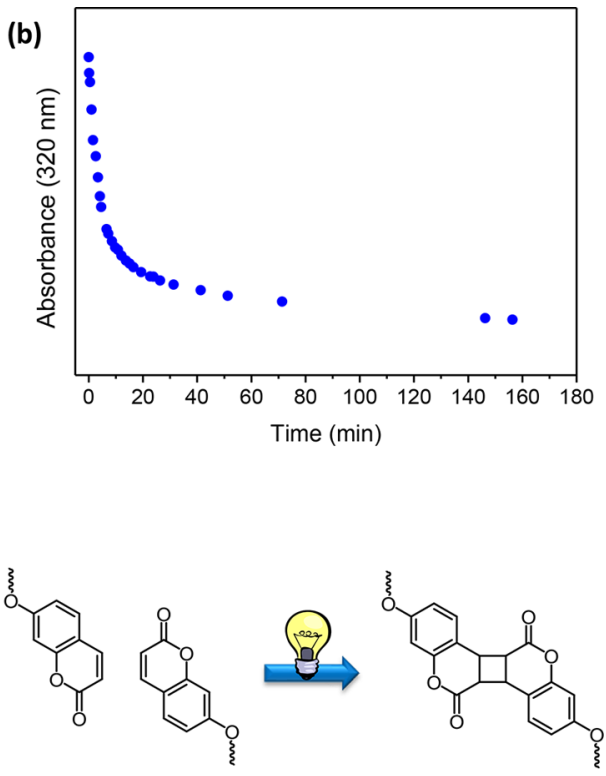

Figure 5. Coumarin photodimerization reaction: (a) UV-vis absorption spectra of a UV-irradiated M-dCou film for different times, (b) change of absorbance over time for a UV-irradiated M-dCou film, and (c) IR spectra of a UV-irradiated M-dCou film for different times.

Network Formation by Coumarin Photodimerization. Once the supramolecular complexes were characterized, the next step consisted of the preparation of cross-linked films. Coumarin units were employed for the cross-linking process by photoinduced $[2+2]$ cycloaddition (so-called photodimerization) in order to lock in the LC arrangement of the complexes.
The coumarin photodimerization was monitored by several techniques such as UV-vis spectroscopy, FTIR, and ${ }^{13} \mathrm{C}$ CPMAS.

The UV-vis spectra of T-dCou and M-dCou in thin film show an intense band at $320 \mathrm{~nm}$ related to the $\pi-\pi^{*}$ of the coumarin units (Figure 5a). Exposure of the supramolecular 
complexes films to $365 \mathrm{~nm}$ UV irradiation caused $[2+2]$ cycloaddition of the coumarin units, and this was consistent with the remarkable decrease of the $\pi-\pi^{*}$ band. After $30 \mathrm{~min}$ of light irradiation only slight changes were further detected in the UV-vis spectra (Figure $5 b$ ).

To examine the structural details of the photo-cross-linking process, irradiated films were studied by FTIR and ${ }^{13} \mathrm{C}$ CPMAS. Irradiation at $365 \mathrm{~nm}$ results in coumarin photodimerization as indicated by the decrease the intensity of the $\mathrm{C}=\mathrm{C}$ stretching band at $1620 \mathrm{~cm}^{-1}$ and the shift of the $\mathrm{C}=\mathrm{O}$ stretching band from 1730 to $1750 \mathrm{~cm}^{-1}$ (Figure 5c). This reaction can also be followed by ${ }^{13} \mathrm{C}$ CPMAS which showed the increase of the intensity of the peak at $44 \mathrm{ppm}$, which corresponds to the cyclobutane ring. Additionally, coumarin photodimerization decreases the intensity of the signals at 149 ppm $\left(C_{C}\right)$ and $113 \mathrm{ppm}\left(C_{\mathrm{B}}\right)$, which corresponds to the $\mathrm{C}=\mathrm{C}$ of the coumarin (Figure 6). Insolubility of the obtained

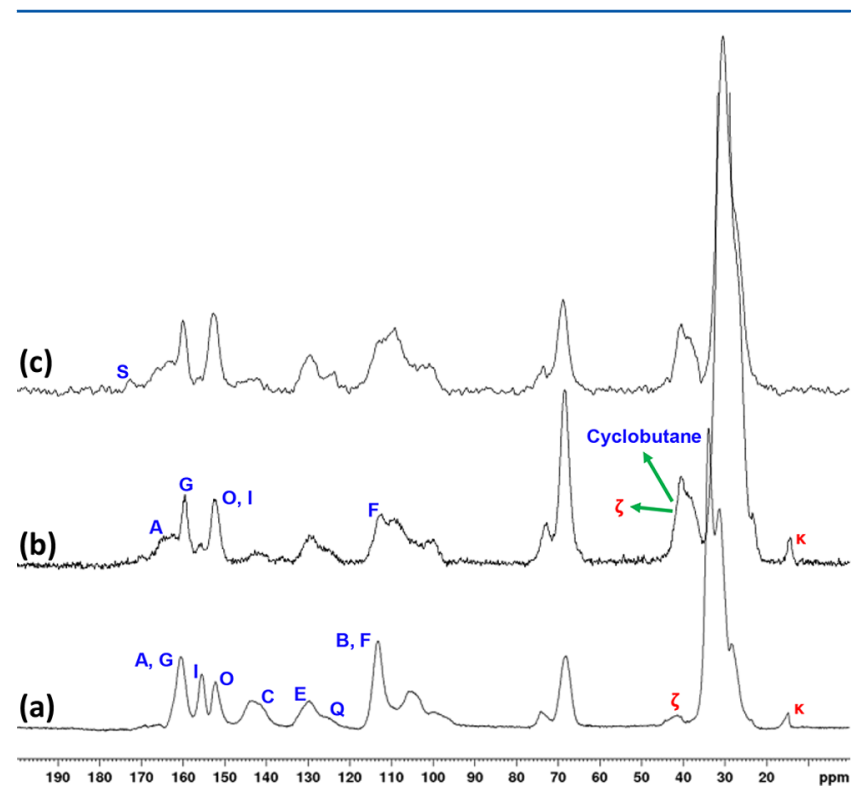

Figure 6. ${ }^{13} \mathrm{C}$ CPMAS NMR spectra of (a) complex M-dCou, (b) Mbased polymer, and (c) M-based nanoporous polymers. All the spectra were recorded at room temperature.

polymer films in common organic solvents, such as dichloromethane, chloroform, tetrahydrofuran, acetone, ethanol, or methanol, confirmed a high degree of coumarin photo-crosslinking to fixate the liquid crystal order.

The XRD diffraction patterns of the complexes after coumarin photodimerization showed retention of the columnar hexagonal arrangement, but the lattice spacings were slightly decreased (ca. $4 \AA$ ) and broadened (Figure 7 and Figure S3). In the both cases, the (110) and (200) reflections could no longer be observed in film due to broadening. These results indicate that coumarin photodimerization can be used to form a crosslinked polymer network and lock in the morphology of the LC phase.

Nanoporous Polymer Formation by the Removal of the Molecular Templates. Self-standing nanoporous polymers were prepared by chemical treatment of the polymer films with $3 \mathrm{M}$ hydrochloric acid solution in ethanol (Figure 8a and Figure S4a). The removal of the template was confirmed by FTIR, gravimetry, ${ }^{13} \mathrm{C}$ CPMAS, and XPS measurements.

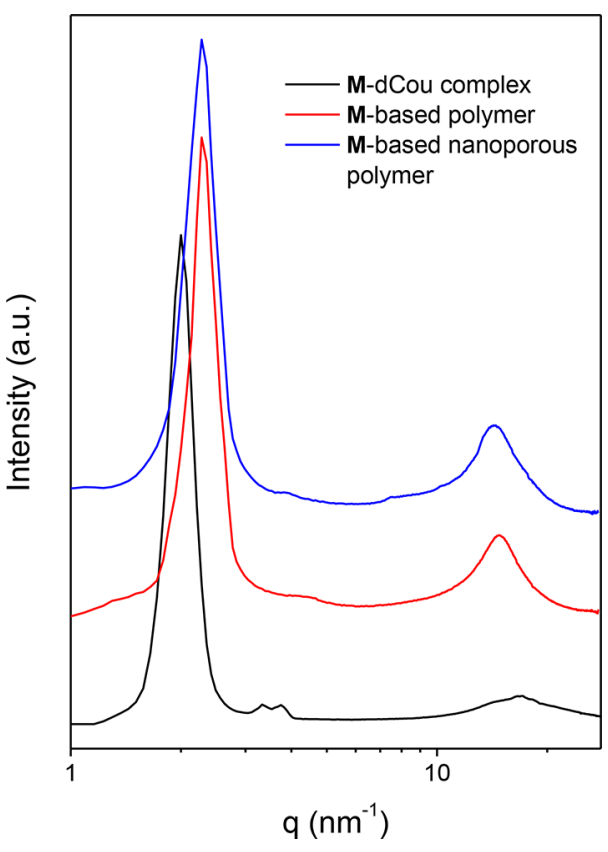

Figure 7. 1D XRD profiles of M-dCou complex, M-based polymer (with template), and $\mathbf{M}$-based nanoporous polymer (after template removal).

The efficacy of $\mathbf{M}$ or $\mathbf{T}$ removal was verified by FTIR spectroscopy (Figure $8 \mathrm{~b}$ and Figure S4b). After template elimination, $-\mathrm{COOH}$ functionalities were expected to be at the pore surface. The IR spectra of the nanoporous polymers showed a new band at around $1675 \mathrm{~cm}^{-1}$ related to free carboxylic acid groups, indicating elimination of the templates. Quantitative template removal was also confirmed by ${ }^{13} \mathrm{C}$ CPMAS analysis (Figure 6c) which showed the disappearance of the signal corresponding to the methyl carbon of the melamine core $\left(C_{\kappa}\right)$. Additionally, a new peak at $173 \mathrm{ppm}\left(C_{\mathrm{S}}\right)$ related to the carboxylic acid groups indicates template elimination.

Another method to quantify the template removal is gravimetry. Polymer films were weighted before and after the chemical treatment with $\mathrm{HCl}$. The films showed a decrease in mass equal to a template removal of $97 \pm 2 \%$ for $\mathbf{M}$-based nanoporous polymer and $96 \pm 2 \%$ for $\mathrm{T}$-based nanoporous polymer.

XPS depth scans were performed by subsequent sputter cycles (etching) in order to quantify the nitrogen-to-carbon ratio throughout the thickness of chemical treated films. The $\mathrm{N} / \mathrm{C}$ ratio versus sputter time (depth) is presented in Figure 8c and Figure S4c. Before template removal, all the film showed a constant $\mathrm{N} / \mathrm{C}$ composition. However, nitrogen was no longer detected in the nanoporous polymers, indicating the quantitative elimination of the templates.

After removal of the template, the structural properties were investigated by XRD. The diffraction patterns of the films showed that lattice parameters of the nanoporous polymer were the same as the native polymer film (Figure 7 and Figure S3). The bulk material retained its columnar hexagonal arrangement even after template removal due to the cross-linking of coumarin units. These results indicate structural integrity and the formation of nanopores with an estimated pore diameter of around 5 and $10 \AA$ for $\mathbf{M}$ - or T-based nanoporous polymers, respectively (Figure S5). 

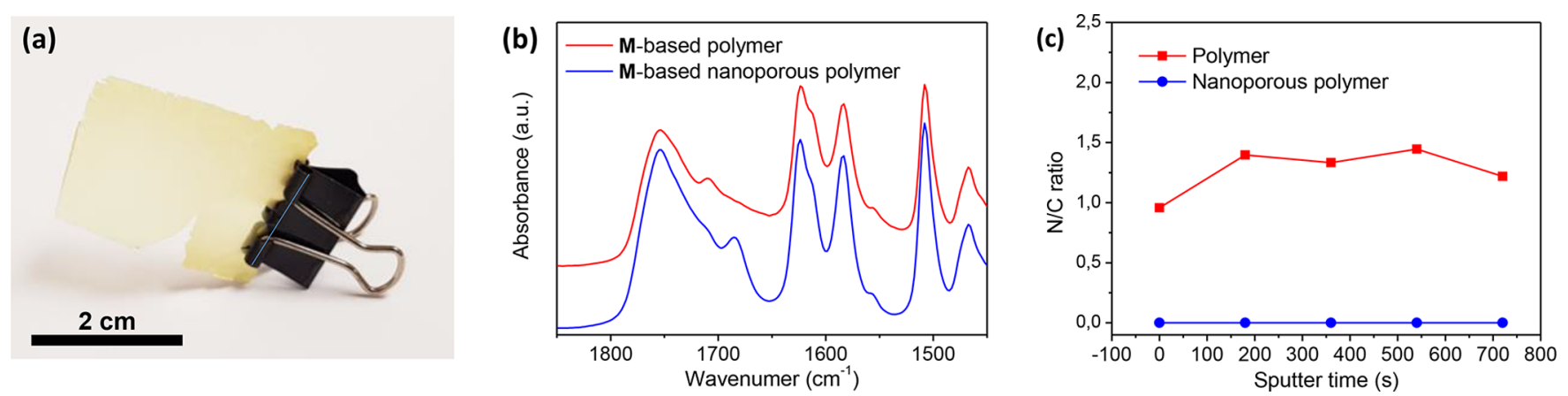

Figure 8. (a) Self-standing M-based nanoporous polymer, (b) FTIR spectra of the M-based polymer and nanoporous polymer, and (c) nitrogen-tocarbon ratio of the M-based polymer and nanoporous polymer as a function of the sputter time (depth) determined by XPS.
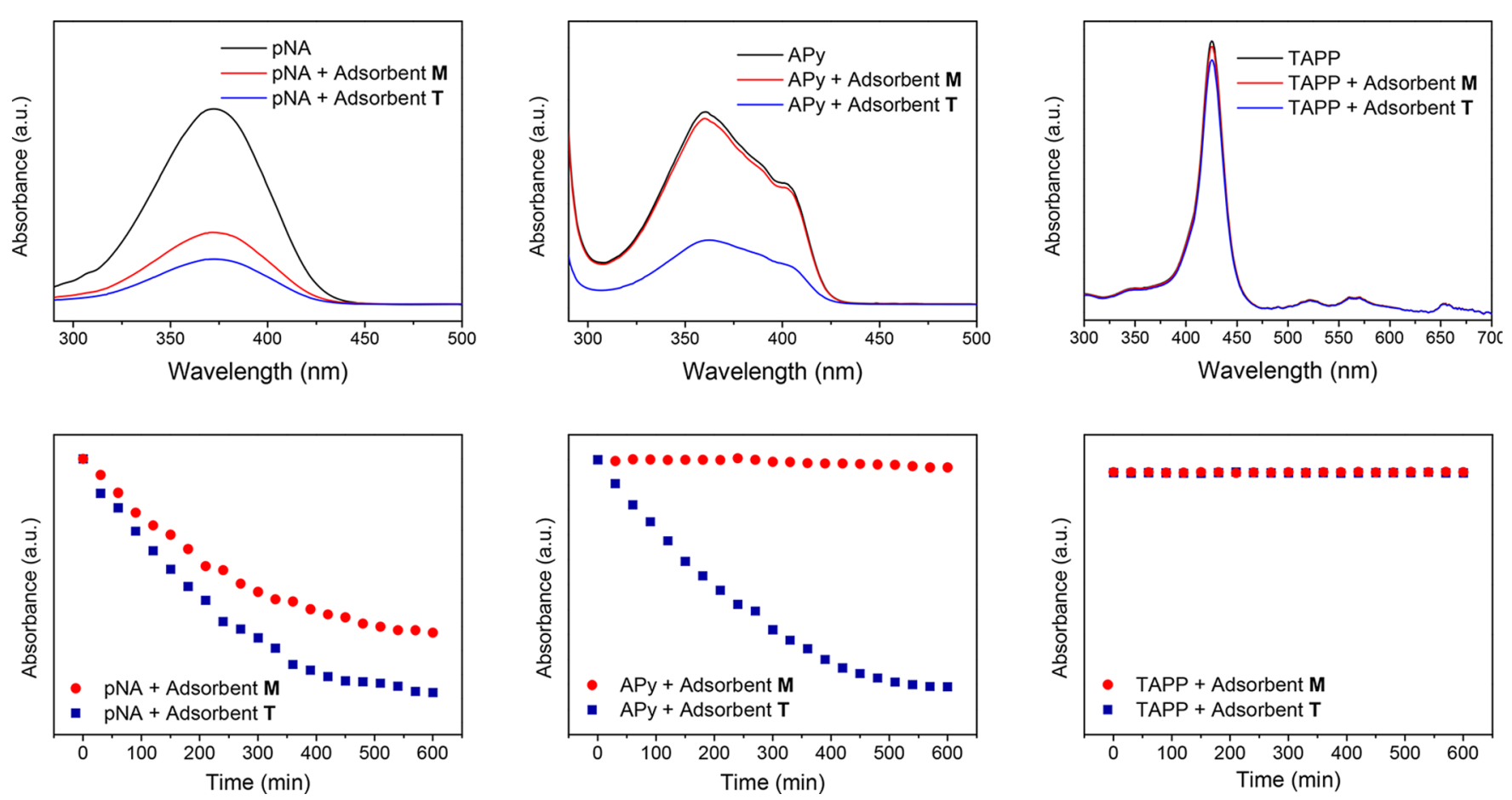

Figure 9. UV-vis spectra before and after adsorption of pNA, APy, and TAPP with $\mathbf{M}$ - and T-based adsorbents (top). Adsorption kinetics of pNA, $\mathrm{APy}$, and TAPP (bottom).

Selective Adsorption of Neutral Molecules. The use of M- and T-based nanoporous polymer with $-\mathrm{COOH}$ functionalities at the pore surface for selective uptake of organic molecules was studied. For this purpose, a variety of molecules with $-\mathrm{NH}_{2}$ functional groups and different sizes were selected: $p$-nitroaniline ( $\mathrm{pNA}$, size $=6 \times 4 \AA$ ), 1 aminopyrene (APy, size $=9 \times 8 \AA$ ), and meso-tetra $(p$-aminophenyl) porphine (TAPP, size $=18 \times 18 \AA$ ) (Figure S7). The adsorption capacity and kinetics of the $\mathbf{M}$ - and $\mathbf{T}$-based porous polymer was investigated by UV-vis spectroscopy (Figure 9). Control experiments were carried out by immersing polymer films (without template removal) in pNA, APy, and TAPP solutions. The solutions with the polymer films had nearly the same absorbance as the initial solutions, revealing its inability to adsorb the molecules without template removal. Adsorption occurs inside the pore and not on the exterior surface of the film.

In the case of the M-based adsorbent with a pore size of around $5 \AA$, only pNA was adsorbed by the $-\mathrm{COOH}$ functionalized pores. This evidence that size-selective adsorp- tion is possible with this polymer. The adsorption kinetics was studied following the absorbance of pNA at $372 \mathrm{~nm}$ over time and shows that adsorption reached a plateau within $8-10 \mathrm{~h}$. The capacity of pNA adsorption was also investigated; $24 \%$ of the carboxylic acid groups were occupied by pNA, which corresponds to 0.72 per disk (each disk consists of three carboxylic acids).

In the case of the T-based adsorbent, with a pore size of around $10 \AA$, both pNA and APy molecules were adsorbed. TAPP uptake in the $-\mathrm{COOH}$ functionalized pores is precluded by size exclusion of the larger TAPP relative to pNA or APy. The adsorption kinetics was also studied revealing that a plateau is reached in $8-10 \mathrm{~h}$. The occupation degree of the carboxylic acid groups with pNA and APy was 42\% (1.26 per disk) and $27 \%$ (0.81 per disk), respectively. It is noteworthy that the adsorption capacity of the T-based adsorbent is higher than the $\mathbf{M}$-based adsorbent due to the larger pore size.

Desorption is important to reuse the adsorbent and to recover valuable adsorbates. It was investigated by UV-vis spectroscopy with fresh, completely pNA filled adsorbents. M- 

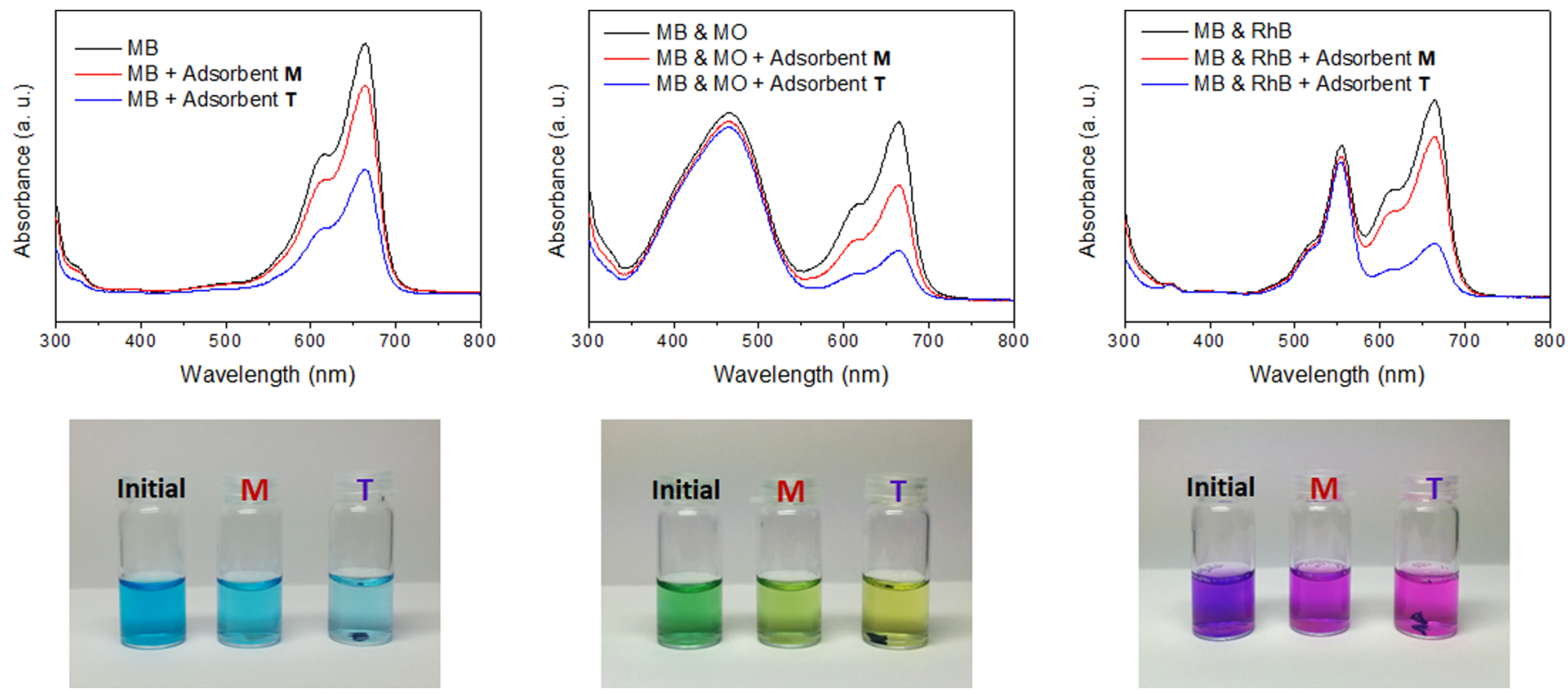

Figure 10. UV-vis spectra before and after adsorption of $M B, M B \& M O$, and $M B \& R h B$ with $\mathbf{M}$ - and T-based adsorbents (top). Vials of MB, MB\&MO, and MB\&RhB before and after adsorption with $\mathbf{M}$ - or T-based adsorbents (bottom).

and T-based adsorbents are able to hold the major fraction of pNA in deionized water. However, after immersing the adsorbents in $0.1 \mathrm{M}$ aqueous solutions of potassium hydroxide, the carboxylate moieties are deprotonated and pNA is removed from the adsorbents. Additionally, the adsorption-desorption was investigated several times, revealing that it is reversible in three repeating cycles (Figure S6), and thus it is possible to reuse these adsorbents many times.

Selective Adsorption of Cationic Dyes. Carboxylic acid functionalized pores were treated with $0.1 \mathrm{M}$ aqueous solutions of potassium hydroxide for $5 \mathrm{~h}$. The formation of porous polymer with $-\mathrm{COOK}$ groups at the pore surface was confirmed by FTIR. The $\mathrm{COOH}$ stretching band was shifted from 1685 to 1560 and $1404 \mathrm{~cm}^{-1}$ (Figure S7).

These adsorbents with -COOK functionalities at the pore surface were used to selective adsorption of ionic dyes. Selective adsorption of molecular species in water with different sizes and charges was carried out with methylene blue (MB), methyl orange ( $\mathrm{MO})$, and rhodamine $\mathrm{B}(\mathrm{RhB}) . \mathrm{MB}$ and $\mathrm{RhB}$ are positively charged dyes, while $\mathrm{MO}$ is negatively charged. The estimated sizes of these dyes are $6 \times 13 \AA$ (MB), $12 \times 16 \AA$ $(\mathrm{RhB})$, and $5 \times 12 \AA$ (MO) (Figure S8).

First, the ability of adsorbing ionic dyes was studied when - COOK functionalized nanoporous polymers where immersed in $\mathrm{MB}$ aqueous solution. Dye adsorption was monitored by UV-vis spectroscopy (Figure 10). MB was adsorbed by the porous polymer, as determined by the decrease of the absorption intensity at $665 \mathrm{~nm}$. The solutions turned from deep blue to less blue, while the film became blue, indicating that the cationic dye is adsorbed from solution. The adsorption capacity was calculated; $9 \%$ for $\mathbf{M}$-based adsorbent ( 0.27 per disk) and $19 \%$ for T-based adsorbent ( 0.47 per disk) of the -COOK groups were associated with $\mathrm{MB}$.

Figure 10 also shows the result of the simultaneous adsorption of $\mathrm{MB}$ and $\mathrm{MO}$ in water. The initial UV-vis spectrum showed two bands: one at $465 \mathrm{~nm}$ belonging to $\mathrm{MO}$ and the second at $665 \mathrm{~nm}$ belonging to MB. After the equilibration with the nanoporous polymers, the UV-vis showed a stable band for MO but a loss of the MB band.
The color of the solution changed from green to yellow after equilibration. The observed selectivity can be ascribed to the difference in the charge of the species.

The size selectivity of the nanopores was demonstrated by simultaneous adsorption of $\mathrm{MB}$ and $\mathrm{RhB}$ from aqueous solutions (Figure 10). After equilibration, the color of the solutions changed from violet to pink, and the UV-vis absorption band of $\mathrm{MB}$ decreased and the $\mathrm{RhB}$ absorption band remained constant. $\mathrm{RhB}$ uptake in the pores is significantly precluded by size exclusion of the larger dye $\mathrm{RhB}$ relative to $\mathrm{MB}$.

Desorption was investigated with fresh, completely MB filled M- and T-based adsorbents in deionized water. The solution became only slightly blue, indicating minor desorption of MB. Nevertheless, after immersing the adsorbents in $3 \mathrm{M}$ hydrochloric acid aqueous solution, the solution suddenly became blue, indicating desorption of $\mathrm{MB}$. At low $\mathrm{pH}$, the carboxylate moieties are protonated and $\mathrm{MB}$ is removed from the adsorbents. Moreover, the adsorption-desorption was investigated several times by UV-vis spectroscopy, which revealed that it is reversible in three repeating cycles (Figure S9), indicating that these adsorbents can be use many times.

\section{CONCLUSIONS}

We have successfully developed a new strategy to obtain selfstanding nanoporous polymers based on the fixation of columnar mesophases by coumarin photodimerization. The size of the pores can be controlled by careful choice of the utilized template. The nanoporous materials with carboxylic acids at the pore surface demonstrate remarkable size selectivity in adsorption experiments. In addition, the chemical nature of the pore can be tuned by in situ treatment with potassium hydroxide. After this base treatment the polymers are able to adsorb cationic dyes and to selectively adsorb cationic dyes over anionic and larger cations. The adsorbed molecules can be desorbed by acid or base treatment; thus, it is possible to reuse these nanoporous polymers.

Our results clearly suggest that these polymers with columnar hexagonal nanopores may be useful in a wide range 
of applications including molecular recognition, filtration, separation, or catalysis.

\section{ASSOCIATED CONTENT}

\section{S Supporting Information}

The Supporting Information is available free of charge on the ACS Publications website at DOI: 10.1021/acs.macromol.8b00067.

NMR, FTIR, POM, XRD, and XPS characterization of 1:3 M-dCou and T-dCou complexes and porous polymers; adsorption and desorption of molecules (PDF)

\section{AUTHOR INFORMATION}

\section{Corresponding Author}

*E-mail: joseluis@unizar.es (J.L.S.).

ORCID

Alberto Concellón: 0000-0002-8932-9085

Albertus P. H. J. Schenning: 0000-0002-3485-1984

Mercedes Marcos: 0000-0001-7056-3181

José Luis Serrano: 0000-0001-9866-6633

\section{Notes}

The authors declare no competing financial interest.

\section{ACKNOWLEDGMENTS}

This work was supported by the MINECO-FEDER funds (project CTQ2015-70174), Gobierno de Aragón-FSE (Research Group E04). The authors acknowledge the use of the SAI (UZ) and CEQMA (UZ-CSIC) Services. A. Concellón thanks MINECO (Spain) for his PhD grant.

\section{REFERENCES}

(1) Zhang, J.; Li, C. M. Nanoporous metals: fabrication strategies and advanced electrochemical applications in catalysis, sensing and energy systems. Chem. Soc. Rev. 2012, 41, 7016-7031.

(2) Shah, M.; McCarthy, M. C.; Sachdeva, S.; Lee, A. K.; Jeong, H.-K. Current Status of Metal-Organic Framework Membranes for Gas Separations: Promises and Challenges. Ind. Eng. Chem. Res. 2012, 51, 2179-2199.

(3) Na, K.; Choi, M.; Ryoo, R. Recent advances in the synthesis of hierarchically nanoporous zeolites. Microporous Mesoporous Mater. 2013, 166, 3-19.

(4) Holst, J. R.; Trewin, A.; Cooper, A. I. Porous organic molecules. Nat. Chem. 2010, 2, 915-920.

(5) Tian, J.; Thallapally, P. K.; McGrail, B. P. Porous organic molecular materials. CrystEngComm 2012, 14, 1909-1919.

(6) Wu, D.; Xu, F.; Sun, B.; Fu, R.; He, H.; Matyjaszewski, K. Design and Preparation of Porous Polymers. Chem. Rev. 2012, 112, 39594015.

(7) Schenning, A. P. H. J.; González-Lemus, Y. C.; Shishmanova, I. K.; Broer, D. J. Nanoporous membranes based on liquid crystalline polymers. Liq. Cryst. 2011, 38, 1627-1639.

(8) Broer, D. J.; Bastiaansen, C. M. W.; Debije, M. G.; Schenning, A. P. H. J. Functional Organic Materials Based on Polymerized LiquidCrystal Monomers: Supramolecular Hydrogen-Bonded Systems. Angew. Chem., Int. Ed. 2012, 51, 7102-7109.

(9) Lugger, J.; Mulder, D. J.; Sijbesma, R.; Schenning, A. Nanoporous Polymers Based on Liquid Crystals. Materials 2018, 11, 104.

(10) Feng, X.; Tousley, M. E.; Cowan, M. G.; Wiesenauer, B. R.; Nejati, S.; Choo, Y.; Noble, R. D.; Elimelech, M.; Gin, D. L.; Osuji, C. O. Scalable Fabrication of Polymer Membranes with Vertically Aligned $1 \mathrm{~nm}$ Pores by Magnetic Field Directed Self-Assembly. ACS Nano 2014, 8, 11977-11986.
(11) Bögels, G. M.; van Kuringen, H. P. C.; Shishmanova, I. K.; Voets, I. K.; Schenning, A. P. H. J.; Sijbesma, R. P. Selective Absorption of Hydrophobic Cations in Nanostructured Porous Materials from Crosslinked Hydrogen-Bonded Columnar Liquid Crystals. Adv. Mater. Interfaces 2015, 2, 1500022.

(12) Feng, X.; Nejati, S.; Cowan, M. G.; Tousley, M. E.; Wiesenauer, B. R.; Noble, R. D.; Elimelech, M.; Gin, D. L.; Osuji, C. O. Thin Polymer Films with Continuous Vertically Aligned $1 \mathrm{~nm}$ Pores Fabricated by Soft Confinement. ACS Nano 2016, 10, 150-158.

(13) Bhattacharjee, S.; Lugger, J. A. M.; Sijbesma, R. P. Tailoring Pore Size and Chemical Interior of near $1 \mathrm{~nm}$ Sized Pores in a Nanoporous Polymer Based on a Discotic Liquid Crystal. Macromolecules 2017, 50, 2777-2783.

(14) González, C. L.; Bastiaansen, C. W. M.; Lub, J.; Loos, J.; Lu, K.; Wondergem, H. J.; Broer, D. J. Nanoporous Membranes of Hydrogenbridged Smectic Networks with Nanometer Transverse Pore Dimensions. Adv. Mater. 2008, 20, 1246-1252.

(15) Kishikawa, K.; Hirai, A.; Kohmoto, S. Fixation of Multilayered Structures of Liquid-Crystalline 2:1 Complexes of Benzoic Acid Derivatives and Dipyridyl Compounds and the Effect of Nanopillars on Removal of the Dipyridyl Molecules from the Polymers. Chem. Mater. 2008, 20, 1931-1935.

(16) van Kuringen, H. P. C.; Eikelboom, G. M.; Shishmanova, I. K.; Broer, D. J.; Schenning, A. P. H. J. Responsive Nanoporous Smectic Liquid Crystal Polymer Networks as Efficient and Selective Adsorbents. Adv. Funct. Mater. 2014, 24, 5045-5051.

(17) Mulder, D. J.; Scheres, L. M. W.; Dong, J.; Portale, G.; Broer, D. J.; Schenning, A. P. H. J. Fabrication and Postmodification of Nanoporous Liquid Crystalline Networks via Dynamic Covalent Chemistry. Chem. Mater. 2017, 29, 6601-6605.

(18) Lee, H. K.; Lee, H.; Ko, Y. H.; Chang, Y. J.; Oh, N.-K.; Zin, W. C.; Kim, K. Synthesis of a Nanoporous Polymer with Hexagonal Channels from Supramolecular Discotic Liquid Crystals. Angew. Chem., Int. Ed. 2001, 40, 2669-2671.

(19) Ishida, Y.; Amano, S.; Saigo, K. Template polymerization of columnar architectures based on the salts of a carboxylic acid and 2amino alcohols: application to the molecular recognition of 2-amino alcohols. Chem. Commun. 2003, 2338-2339.

(20) Ishida, Y.; Amano, S.; Iwahashi, N.; Saigo, K. Switching of Structural Order in a Cross-Linked Polymer Triggered by the Desorption/Adsorption of Guest Molecules. J. Am. Chem. Soc. 2006, 128, 13068-13069.

(21) Amano, S.; Ishida, Y.; Saigo, K. Solid-State Hosts by the Template Polymerization of Columnar Liquid Crystals: Locked Supramolecular Architectures around Chiral 2-Amino Alcohols. Chem. - Eur. J. 2007, 13, 5186-5196.

(22) Lee, J. H. Fabrication of conjugated polymeric nanochannels from star-shaped supramolecular liquid crystals containing two different photoreactive groups. Liq. Cryst. 2014, 41, 738-746.

(23) Li, C.; Cho, J.; Yamada, K.; Hashizume, D.; Araoka, F.; Takezoe, H.; Aida, T.; Ishida, Y. Macroscopic ordering of helical pores for arraying guest molecules noncentrosymmetrically. Nat. Commun. 2015, 6, 8418.

(24) Bögels, G. M.; Lugger, J. A. M.; Goor, O. J. G. M.; Sijbesma, R. P. Size-Selective Binding of Sodium and Potassium Ions in Nanoporous Thin Films of Polymerized Liquid Crystals. Adv. Funct. Mater. 2016, 26, 8023-8030.

(25) Feng, X.; Kawabata, K.; Kaufman, G.; Elimelech, M.; Osuji, C. O. Highly Selective Vertically Aligned Nanopores in Sustainably Derived Polymer Membranes by Molecular Templating. ACS Nano 2017, 11, 3911-3921.

(26) Gracia, I.; Romero, P.; Serrano, J. L.; Barberá, J.; Omenat, A. Templated nanoporous membranes based on hierarchically selfassembled materials. J. Mater. Chem. C 2017, 5, 2033-2042.

(27) Barberá, J.; Puig, L.; Romero, P.; Serrano, J. L.; Sierra, T. Propeller-like Hydrogen-Bonded Banana-Melamine Complexes Inducing Helical Supramolecular Organizations. J. Am. Chem. Soc. 2006, $128,4487-4492$. 
(28) Feringán, B.; Romero, P.; Serrano, J. L.; Giménez, R.; Sierra, T. Supramolecular Columnar Liquid Crystals Formed by Hydrogen Bonding between a Clicked Star-Shaped s-Triazine and Benzoic Acids. Chem. - Eur. J. 2015, 21, 8859-8866.

(29) Concellón, A.; Liang, T.; Schenning, A. P. H. J.; Serrano, J. L.; Romero, P.; Marcos, M. Proton-conductive materials formed by coumarin photocrosslinked ionic liquid crystal dendrimers. J. Mater. Chem. C 2018, 6, 1000-1007.

(30) Zhao, L.; Loy, D. A.; Shea, K. J. Photodeformable Spherical Hybrid Nanoparticles. J. Am. Chem. Soc. 2006, 128, 14250-14251.

(31) Fan, W.; Tong, X.; Li, G.; Zhao, Y. Photoresponsive liquid crystalline polymer single-chain nanoparticles. Polym. Chem. 2017, 8, 3523-3529.

(32) Maddipatla, M. V. S. N.; Wehrung, D.; Tang, C.; Fan, W.; Oyewumi, M. O.; Miyoshi, T.; Joy, A. Photoresponsive Coumarin Polyesters That Exhibit Cross-Linking and Chain Scission Properties. Macromolecules 2013, 46, 5133-5140.

(33) Concellón, A.; Marcos, M.; Romero, P.; Serrano, J. L.; Termine, R.; Golemme, A. Not Only Columns: High Hole Mobility in a Discotic Nematic Mesophase Formed by Metal-Containing PorphyrinCore Dendrimers. Angew. Chem., Int. Ed. 2017, 56, 1259-1263. 